University of New Hampshire

University of New Hampshire Scholars' Repository

$1-2017$

\title{
Christians' Cut: Popular Religion and the Global Health Campaign for Medical Male Circumcision in Swaziland
}

\author{
Casey Golomski \\ University of New Hampshire, Durham, casey.golomski@unh.edu \\ Sonene Nyawo \\ University of Swaziland, snyawo@uniswa.sz
}

Follow this and additional works at: https://scholars.unh.edu/anth_facpub

Part of the African Languages and Societies Commons, African Studies Commons, Christian

Denominations and Sects Commons, Christianity Commons, Community Health and Preventive Medicine

Commons, Ethics in Religion Commons, Gender and Sexuality Commons, Health Policy Commons, International Public Health Commons, Medical Humanities Commons, Medicine and Health Commons,

Missions and World Christianity Commons, Other Feminist, Gender, and Sexuality Studies Commons,

Public Health Education and Promotion Commons, Social and Cultural Anthropology Commons,

Sociology of Culture Commons, Sociology of Religion Commons, and the Women's Health Commons

\section{Comments}

This is an Author's Original Manuscript of an article published by Taylor \& Francis in Culture, Health \& Sexuality in 2017, available online: https://dx.doi.org/10.1080/13691058.2016.1267409

\section{Recommended Citation}

Golomski, Casey and Nyawo, Sonene, "Christians' Cut: Popular Religion and the Global Health Campaign for Medical Male Circumcision in Swaziland" (2017). Culture, Health \& Sexuality. 7.

https://scholars.unh.edu/anth_facpub/7

This Article is brought to you for free and open access by the Anthropology at University of New Hampshire Scholars' Repository. It has been accepted for inclusion in Anthropology Scholarship by an authorized administrator of University of New Hampshire Scholars' Repository. For more information, please contact

Scholarly.Communication@unh.edu. 


\section{AUTHORS}

Casey Golomski and Sonene Nyawo

TITLE

Christians' Cut: Popular Religion and the Global Health Campaign for Medical Male Circumcision in Swaziland

\section{ABSTRACT (164)}

Swaziland faces one of the worst HIV epidemics in the world, and is a site for a current global health campaign in sub-Saharan Africa to medically circumcise the majority of the male population. Given that Swaziland is also majority Christian, how does the most popular religion influence acceptance, rejection, or understandings of voluntary medical male circumcision (MMC)? This article considers interpretive differences by Christians across the Kingdom's three ecumenical organizations, showing how a diverse group people singly glossed as Christian in most public health acceptability studies critically rejected the procedure in unity, but not uniformly. Participants saw MMC's promotion and messaging as offensive and circumspect, and MMC to confound gendered expectations and sexualized ideas of the body in Swazi Culture. Pentecostal-charismatic churches were seen as more likely to accept MMC, while traditionalist African Independent Churches rejected MMC. The procedure was widely understood to be a personal choice, and adhered to New Testament-inspired commitments to metaphorical circumcision as a way to receive God's grace.

\section{KEYWORDS}

Medical male circumcision - Christianity - global health - ecumenism - gender 
MAIN TEXT (7499 words, including main text, references, headings, notes)

\section{Introduction}

Voluntary medical male circumcision (MMC) has been promoted by global public health entities as a mode of HIV prevention for almost a decade. In the early 2000s, large-scale randomized controlled trials in East and Southern Africa showed reductions in the risk of HIV female-to-male transmission by roughly $60 \%$ and decreased disease incidence (Auvert et al. 2005, Bailey et al. 2007, Wawer et al. 2009). In their wake, the World Health Organization (WHO) and Joint United Nations Programme on HIV/AIDS (UNAIDS) developed recommendations based on these studies to scale-up MMC in 14 sub-Saharan African countries with high HIV prevalence and low male circumcision coverage. Their objective was to reduce HIV incidence, and, secondarily, incidence of urinary tract infections, sexually transmitted infections, and the human papillomavirus by circumcising $80 \%$ of the male population in these countries by 2015 .

One of these targeted countries was the Kingdom of Swaziland. The second smallest country and last absolute monarchy in Africa with a population about 1.3 million, Swaziland could be labeled a ground zero for the global HIV epidemic, with high disease incidence (2.4\%) and the world's highest prevalence (26.3\%) since at least 2006 (Bicego et al. 2013). In conjunction with the Ministry of Health, global health entities and service providers like Family Life Association of Swaziland and Population Services International have been offering MMC locally since 2006, including partnering with the United States Agency for International Development (USAID) in 2009 to promote early infant male circumcision. In 2011, with a 
United States' President's Emergency Plan for AIDS Relief (PEPFAR) contract of \$15.5 million, the global development corporation Futures Group, now Palladium, began an accelerated saturation initiative to reach the target of circumcising 152,000 males in a year.

In the effort to create an enabling environment for behavior change through a multisectoral approach, they partnered with the Kingship and government, establishing ten teams of doctors, nurses, counselors, hygienists and administrative staff to operate in the country's four regions, and intensively canvassing through conventional media and community-based agents in a campaign titled Soka Uncobe ("circumcise and conquer"). Low clinical turnout quickly became apparent, and particular groups of males were specifically targeted to drive recruitment goals, including school-going youth, soldiers, and laborers in sugar-cane plantations (Mkhwanazi 2016). When the implementers withdrew in 2012, the results, to quote one Futures Group executive, were "disappointing." About 11,000, chose to be cut, or about $7 \%$ of the original target. Why then did this global health campaign supposedly "fail", in the words of one PBS story on the matter (Smith 2012, Adams and Moyer 2015, Mkhwanazi 2016)?

For actors and agencies of global health, MMC represents a profound prevention approach, but portends obstacles in asking a historically non-circumcising traditionalist society to undertake the procedure. Given the immense scale of the intervention, as both a technodevelopment project and one shot through both local and global politics - King Mswati III, the political leader and spiritual guardian of the nation, fully supports the campaign to date-we were keen to see how the campaign intersected with other major social forces that affect everyday life in Swaziland. Namely, we ask how the most popular local religion of Christianity is related to MMC's uptake. 
[Insert Figure 1] Figure 1: Public health message, southern Swaziland, 2011: small store adjacent to the chief's compound, umphakatsi with a public health message saying: "Circumcise and conquer; I conquered! I circumcised! Safer from HIV.” Photo by Casey Golomski

Legislatively, Swaziland has no official religion, but everyday practices point to Christianity's overriding popularity. Most Swazis identify as Christian (International Religious Freedom Report 2012). Forms of Swazi Traditional Religion like divination, herbal healing, and environmental and ancestral spirit veneration also make up this religious landscape and elide with Swazi Culture, a reified set of practices and values shored up by the monarchy in national ceremonies, clothing, tourism, heritage programming, and everyday ideations of custom. Christian churches affiliate to three ecumenical bodies: the Swaziland Conference of Churches (SCC), the Council of Swaziland Churches (CSC), and the League of African Churches in Swaziland (LACS).

Churches formerly established by European and United States missionaries founded the SCC in 1929. The overriding aim of SCC has been to foster cooperation among the various mission churches engaged in Christian evangelism and includes several Protestant churches like Church of the Nazarene, Assemblies of God, and the Evangelical Church. SCC experienced a schism in 1976 when liberal members withdrew to form the CSC, which includes the Catholic, Methodist, and Anglican churches. While SCC has primary aims in church-planting and conversion, CSC strives to address social concerns in society such as poverty, underdevelopment and injustice.

Unlike SCC and CSC, King Sobhuza II formed LACS in the early 1940s in liaison with clergy belonging to African Independent Churches and in response to attempts by the British 
colonial government and some European missionaries to ban these churches in Swaziland. Given Sobhuza's legitimation and mentorship role in the formation of this body, the constitution of LACS recognizes the King as its life-long patron, and LACS has been credited with rendering unequivocal support for Swazi Cultural nationalism. Like CSC and SCC, LACS aims to promote fellowship and unity among churches. Aside from a few limited instances (International Religious Freedom Report 2012), there is an overall climate of religious tolerance in Swaziland and between different Christian churches.

An approach that considers how diverse forms of a dominant religion affect health and wellbeing also supplements what is a surprising paucity of the variable in MMC studies. Many acceptability studies - benchmark research meant to gauge local inhibitions to public health interventions - tend to conceptually collapse "religion" and "culture" into a singular variable (Drain et al. 2006, Khumalo-Sakutukwa et al. 2013, Ssekubugu et al. 2013, Westercamp and Bailey 2007). Specific to Swaziland and MMC, religion has not been a central analytic or topical focus, and it makes an inconsistent appearance as a variable that may or may not affect uptake (Adams and Moyer 2015, Jarrett et al. 2014, Khumalo 2014, Maibvise and Mavundla 2014).

This issue of religion and global health matters locally too, as self-identified Christians try to reconcile preventive health and social responsibilities to spouses and lovers in sexual relations with the moral stipulations promoted in churches in a culturally over-determined public sphere. At the beginning of our research, it was evident that the colloquial jury was still out on the matter. For example, the Church Forum-Swaziland is an organization comprising the Kingdom's three ecumenical bodies with aims to address issues of HIV/AIDS, health and social welfare. Recently, this organization declared its "official standing" on MMC at a press conference in Manzini, where Executive Director Reverend Zwanini Shabalala reported that 
Forum members met to reach "common ground about benefits of adult and early infant MMC," and stated they would "encourage our members to remove their foreskin for purposes of preventing HIV" (Mavuso 2015). Two weeks later, Swaziland's national radio service aired its weekly health program with a panel comprising Shabalala and three other pastors to talk about MMC. In their presentation, they made sweeping statements that Christians now understood the procedure's importance. However, when listeners were invited to call in, four male callers occupied the hour making comments against the procedure. In their concluding remarks, the panelists admitted the public had mixed feelings about MMC, hence the need for an aggressive educational campaign.

\section{An Ecumenical Approach}

What then are perceptions of MMC for ordinary members across the three ecumenical bodies? How might perceptions of MMC across churches align, differ and affect uptake? Overall, we argue that for some self-identified Christians in Swaziland, their non-uptake of the procedure can partially be explained by religiously inspired perceptions of culture, gender, and inequality that, in total present a unified, yet not uniform challenge to global health interventions. We take what we call an ecumenical approach to ask our research questions and situate our findings, derived from our interdisciplinary collaboration as a cultural and medical anthropologist (Golomski) and a theologian of gender and sexuality (Nyawo). Ecumenism comes from the Greek term oikoumene, meaning "the entire inhabited earth". Ecumenical theology speaks to issues concerning unity and the mission of the Christian church worldwide. Amanze (2006) notes that church unity in this context does not necessarily entail uniformity of doctrine, worship, and governance. Instead, it can denote unity in reconciled diversity where denominations are neither fiercely divisive nor paternalistic, nor is there ideological harmony 
between churches and state, a conceptual move that also disrupts prevailing interpretations about state-driven religious and cultural uniformity, often conceptualized as 'hegemony', in this unique field-site (Kumalo 2013, Levin 1997).

In this regard, an ecumenical approach to perceptions of biomedical technologies and global health interventions shows how divergent acts of tolerance, acceptance, or rejection of these forms coexist within interrelated religious communities. Our approach also drives new directions in the anthropology of Christianity in Africa with respect to the ways the religion shapes differences between social institutions and how divergence or convergence on issues of gender shapes identities (Robbins 2014) and how ecumenism may help conceptually frame these processes (Golomski 2015). We also follow Africanist medical anthropologists who show that Christianity and its organizations influences uptake, use of, and access to HIV/AIDS biomedical technologies (Dilger, Burchardt, and van Dijk 2010, Burchardt 2014, 2015). In one of the few instances mentioning ecumenism in this regard, Burchardt (2015) notes that American Evangelical churches tended to partner with locally well-established ecumenical organizations in the Cape Town area, rather than indigenous churches to realize their HIV/AIDS related health, development and social welfare projects.

Finally, paying attention to religious organizational influence on global health programs also aligns with human rights scholarship. Mark Goodale (2006: 5), in a discussion of competing notions of human rights, coined the term "ecumenical anthropology," an approach "that draws from an internal epistemological pluralism to better understand the pluralism-whether irreducible or not — that characterizes" practices of a particular social field. Our approach and findings point to the way diverse religious perspectives unify to both strengthen communities' sense of the right to make educated personal choices about health, and affirm their toleration of 
ideological and practical differences - what we assume to be a staple of multicultural democracies, and here, surprisingly, for a hegemonically monocultural absolute monarchy.

\section{Methods}

Given the multiple connotations surrounding circumcision generally, and that it was a loaded public issue, we used qualitative methods of semi-structured, open-ended questioning in both interviews and focus groups so that participants would have greater license to explain what they knew about it. Golomski designed a set of questions that was refined to be used for both individual interviews and a set of focus groups, by conceptualizing and organizing questions so to lead participants to talk about circumcision with regards to: the Soka Uncobe campaign, gender and sexuality, culture, and religion, namely biblical knowledge and Christian organizational identities. We aimed to solicit potential practical and theological distinctions of lay members and leaders of churches representing the three ecumenical bodies, and conducted three focus groups, each based out of a church representing each body.

Nyawo recruited participants purposively from the urbanized Manzini district, as it draws in many rural and peri-urban citizens for work and worship. Nyawo contacted leaders in each church, who made announcements during worship services soliciting participation of interested congregants as focus group members. Each group had nine participants (27 total), including 19 men and 8 women, ranging in age from 10-50 years. ${ }^{1}$ Three participants identified as married, four did not disclose their marital status, and the remaining 20 were single. We also conducted seven individual interviews: two male church leaders from the CSC church and the LACS church, and one female and one male leader from the SCC church, all of whom were interviewed 
before their respective churches' focus groups. We also interviewed one male self-identified "traditionalist" at his home who did not belong to any church.

Nyawo ran the focus groups and interviews in siSwati with the aid of a bilingual EnglishsiSwati graduate student, collecting data between December 2014 and January 2015. At the time of the study, both authors had institutional-disciplinary homes in the humanities, whose faculties did not require the study's review by a human subjects research board. Still, we disclosed to them that their participation was voluntary, their risk minimal, and their identities anonymized insofar as personal names and particular churches would not be published. All who showed up agreed to participate after these explanations. We did not ask whether or not participants or their consociates underwent circumcision themselves, although some volunteered this information. We also consulted archival resources and objects of the collection at Umsamo weSive, the National Museum in Lobamba to supplement data collected in the focus groups and interviews.

The graduate student translated and transcribed the findings in a MS Word document. Golomski and Nyawo reconvened in-person in February 2015 to looking for common themes and divergent perspectives from members of the different churches. We used discourse analysis to situate participants' perspectives in relation to configurations of power embedded in their local socio-historical context (Johnstone 2007), and we corroborated participants' perspectives based on our respective long-term residence and ethnographic and qualitative research on medicine, gender, sexuality, and religion in Swaziland.

\section{Findings}

\section{Global Health: Circumspect Circumcision}


All participants understood MMC to be a health related phenomenon, one CSC man saying it began like "big bang" linked to the Ministry of Health and several international organizations. All participants identified Soka Uncobe's goal as curbing HIV transmission, sexually transmitted infections, and other diseases for the improvement of men's sexual health, with members of the CSC describing how MMC prevented "dirt" from accumulating in the (now-removed) foreskin. The procedure was understood to involve both physiological and psychosocial aspects. Three interviewees (SCC female, CSC male, LACS male) reported that the foreskin of the penis was surgically removed following anaesthesia, the SCC female saying it was a painful procedure with excessive bleeding and enduring wounds. The LACS focus group agreed it was painful, but the pain minimal. As for psychosocial aspects, all participants suggested patients increased their education about their health, and negatively for the LACS interviewees, decreased men's sexual stimulation.

While all participants claimed that the goal of reducing HIV nationally was generally important, most were critical of MMC as a public and global health project, describing how the project operated on problematic presumptions of sexuality, health, and gender. For example, some suggested that those working on the campaign were disingenuous with regards to the procedure's salvific qualities, and viewed the relationship between the state and global health entities with suspicion, pointing to ways each would benefit monetarily through grants and access to research populations. One male interviewee from the SCC church said,

I also think there are a lot of exaggerations and fabrications about circumcision, which unfortunately water down any effort to promote it in our society. In my view, what is important in this morally corroded society is not to circumcise but to be well behaved. I also think that the 
stereotypes that 'women are sexually satisfied by a circumcised man', should be empirically tested for validity. For me, such is just a marketing strategy, which unfortunately has long-term effects.

In his view, the general importance of the campaign was superseded by concerns that it was publically misconstrued and disrupted moralized forms of sexual reproduction. The idea that it was incorrectly introduced aligned with a theme that MMC was possibility rooted in unsavory political and financial alliances between the Swazi and foreign governments and NGOs. CSC and LACS focus group members noted that these campaigns and their promoters had "ulterior motives" and were compelled by "money" rather than social, religious or health concerns for the population or churches at large.

Several participants zeroed in on material incentives that accompanied the campaign, citing that gifts distributed by clinics and NGOs seductively clouded peoples' critical examination of MMC. One LACS interviewee, echoing the LACS focused group noted, "however, some young men are drawn by pull factors such as T-shirts, bottle juices, tracksuits which are distributed as incentives to every male that visits the clinics to circumcise." A woman from the SCC focus group highlighted how youth came to this perception through the campaign:

I have a younger brother who is 18 and he is circumcised. Ever since he performed this surgical procedure he has been sleeping around with many girls of his age. His friend partly attributes this behavior to the manner in which circumcision is promoted in the schools. According to the friend, promoters who visit their school would use a metaphor of a bush knife in their illustrations to explain that circumcision also strengthens your manhood. There is the misconception that the 'bush 
knife' [penis] is sharpened by circumcision, and young men develop insatiable sexual appetite. Such language can be destructive because it dupes young men to think that they are justified to sleep around... The advertisements and slogans for circumcision are persuasive and indirectly manipulative. For example, lisoka lisoka ngekusoka, which implies that you are not a real man unless you are circumcised. Some adverts would even state that once you circumcise you become lichawe, a hero.

While this is a stark example of negative interpretation, all the focus groups noted that the campaign was marred by public misinformation. The most troubling surrounded perceptions of post-surgical clinical practices. All three focus groups repeated a popular rumor that circulated in 2011 and 2012 that excised foreskins were being re-used for (traditional) medicinal purposes, an otherwise morally ambiguous facet of "Swazi Culture"” for most self-identified Christians.

\section{Swazi Culture: Predicaments of Gender, Body and Dress}

As other studies have collapsed "culture" and "religion" as a single variable, we were keen to understand how participants responded to direct questions about "Swazi Culture," or emasiko emaSwati, which better translates as Swazi "customs." For all participants, circumcision was in no way said to be part of contemporary culture in Swaziland. It was instead understood to be a personal decision about one's health, and all participants variably suggested a deeper history for the procedure as non-biomedical phenomenon in cross-cultural perspective with regards to: gender and generation; evocations of masculinity through adornment practices; and to the history of the formation of the Swazi nation in regional perspective. 
In elaborating on its cultural dimensions of circumcision, several participants explained the procedure generally in terms of masculine identities over the life course. The traditionalist male explained these elements using his family history and cultural nomenclature:

My grandfather happens to have a second name, Sokalemali, which roughly translates to 'a circumcised charmer that has money.' There is a second indicative word lisokanchanti, which exists in Swazi vocabulary, and it means 'one who was circumcised first, and earlier than the rest.' This is the word used to refer to first-born sons who, if circumcision once existed they would have been circumcised before their younger brother.

CSC focus group members similarly cited the work lisoka, but no other participants noted related terms or folkloric songs or narratives involving circumcision. The fact that circumcision is missing from this archive points to its unconventionality. Members of the SCC focus group discussed it comparatively as a male rite of passage, noting how South African Xhosa young male initiation contrasted to Swazis whose practices did not involve a ceremonial cut.

The traditionalist and the two CSC interviewees explained how circumcision in Swaziland "died down" during a historical period of regional social and political upheaval in the mid-nineteenth century, the Mfecane, which involved fighting among African polities and encroaching European colonial forces. One CSC interviewee explained how circumcision declined because warrior regiments had to "remain strong and fit to face opponents. Circumcision would confine them and they would be vulnerable to their rivals, thus risking the group's security." Today, as noted by these participants, membership in the regiments, emabutfo continues as a ceremonial and occupational endeavor involving other rites, as well as adorning customary attire, imvunulo. All the focus group discussions about MMC vis-à-vis culture turned on one particular item that also materialized forms of age-related masculinity: umncadvo. 
[Insert Figure 2] Figure 2: umncadvo penis cover, National Museum, Lobamba, 2011: Photo by Casey Golomski

Umncadvo (variably spelled umncandvo, umncwandvo, umcwatfo) is a penis cover. Respectfully called "traditional underwear" in Swazi English, umncadvo is made from the dried, hollowed out fruit of the African Dog Rose tree, oncoba spinosa. Once smoothed out and hardened it is placed on a flaccid penis by pulling up the foreskin and screwing it down around the head. Several participants in this study and others attributed various functions to the penis cover and that the cover protects the genitalia from chaffing against the customary attire of emahiya textiles or emajobho animal loinskins. Looking back to our personal research archives to supplement these findings, Golomski interviewed a nurse in the Hhohho district in 2009 who said wearing the cover essentially prevents the man from licentiously becoming erect, as it only ably fits a flaccid penis. In 2010, Golomski also interviewed a Mbabane woman estranged from her husband who explained that in customary divorce proceedings, the couple and family members divide piles of each spouses' belongings in front of the house to publicly clarify the division of property. The umncadvo was placed on the top of the man's belongings, signaling the end of marital fidelity.

Two men in the LACS focus group and the traditionalist described how penis covers were hygienic, customary forms of clothing compromised by circumcision. "We grew up knowing that should one's penis head be "stung' by a fly" (kusutelwa yimphungane), it would be bare, and that meant one's penis to be without the foreskin, [which] was unacceptable," a LACS man said. "This might explain the aged cultural practice of covering the penis head with umncadvo to protect it from the dangers of being 'stung' by flies." The traditionalist explained "the daily dress code for Swazi males has changed to Western clothes which completely protect 
the penis from flies. Even for those who still wear traditional clothes, whether rarely or frequently, the dictates may still be compatible as long as circumcision doesn't make wearing the umncadvo impossible." "Dictates" here refer to stipulations at social events that call for imvunulo. In their view, circumcision removed the body part that keeps this clothing item functional, in turn disqualifying demonstrations of masculinity in settings governed by traditionalist, gendered sociability.

\section{Circumcision of the Heart: Biblical and Ecumenical Perspectives}

In contrast to Swazi Culture, Christianity conveyed a different set of principles surrounding circumcision. All the focus groups noted it was an ancient Jewish rite of biblical origin. Despite being a concept that many Swazis would be familiar with as bible-readers, their textual or interpretive knowledge of bibical circumcision was more scant. Most gave general distinctions between injunctions for and against circumcision that corresponded to verses in the Old Testament (OT) and the New Testament (NT). ${ }^{3}$ Several people noted that the bible was "contradictory" or "conflicting" in this regard.

Participants in the focus groups overwhelmingly pointed to the importance of circumcision and favoured one particular NT reading: Acts 15. It recounts the Conference of Jerusalem, where there was a debate about whether or not Gentiles should circumcise before becoming members of the Christian church. Paul the Apostle represented a liberal position in this debate that gets translated locally in Swaziland as "circumcision of the heart," meaning that physical circumcision is not as important or necessary to show one's faith in God. As one man from LACS said, "The most important thing to me, even though I was circumcised, is the inward circumcision which emphasizes changes in the inside of the person [to be born again]." A man in a CSC focus group explained, "what happens to the body is not so important." Paul's perspective 
in the new covenant supersedes that of the OT in Genesis." In this regard, physical circumcision, and by extension MMC, was not taken to be evidence for one's Christian identity, but stood in as a powerful historical metaphor for commitments to receive God's grace.

Again, many acceptability studies tack "religion" and "culture" into a single variable, and we were interested in interrogating potential intersections between the two. Participants found them to be too distinct. Our questions "Do you think what the bible and Swazi culture each says about circumcision can come together or be compatible? How so?" turned up curt, negative responses, with all participants noting Swazi Culture had no practical grounds for the procedure and the bible was contradictory on the matter. "There is nothing to compare," explained one man in an LACS focus group. The two SCC interviewees explained that some elements of Swazi Culture paralleled practices found in the OT like polygyny and levirate marriage, but the two traditions differed on circumcision. For Jewish people in the OT it was a priority, and for contemporary Swazis it was not, at least not culturally.

Turning attention to ecumenism, we asked whether or not different churches had different opinions on MMC, probing with example churches representing each ecumenical body. Differences between churches ran along several axes. Our two LACS and one SCC interviewee, named LACS churches as less likely to take up circumcision because members were supposedly less educated and, in the words of one man from the LACS focus group, were "an indigenous religious group" and "may not fully or readily accept circumcision, especially because it's not a cultural practice.” The LACS group said MMC was not promoted because it was an immodest topic of discussion in their "older" or "traditional" churches. In contrast, "new" churches, which included oft-cited "ministries"-Pentecostal type churches sometimes associated with the SCC - were thought to be more for the procedure. One SCC focus group member said new 
churches attached "new meanings to the scripture, which conform to the needs of the twenty-first century." This stance was chalked up in the idea that SCC church members were better educated or had occupational knowledge of biomedicine. Namely, their members included nurses or doctors. One man from a LACS church pondered, "These days there are those [churches] like, tichwichiwchwi [sarcastic expression indicating people with education], but perhaps [circumcision] goes on better there because they are educated whereas progress is slower in our Zionist church.)." The CSC and LACS focus groups also noted that newer churches promoted or talked about circumcision because it had something to do with "money," a feature of Pentecostal churches' prosperity gospel teachings. Some focus group members were uncertain about other churches' practices because they did not visit other churches, but most were of a consensus that "to differ is to be human," as one CSC focus group member noted, and that churches would differ in doctrines, ethics, and practices.

Participants overwhelmingly reported that MMC was not a topic of discussion by pastors at church worship services, noting that services were about delivering the Word of God and not a space for health messaging. However, most gave blanket admission that talking about the procedure in church would be beneficial in theory because church was a public social setting. In this regard, some told us that as influential leaders, pastors should be educated on public health issues so as to give accurate and balanced information to concerned church members. However, the claim for educated, pastoral counsel seemed to be geared toward informing church members about circumcision so they could be additionally or independently critical of it before deciding whether the procedure was right for them. One member of SCC had programmatic ideas about how to do this, using the Swazi Cultural stipulations of age-grades: 
Personally, I believe the Bible has solutions to life challenges that we face even today; for example it states that 'do not commit adultery' and to me that inhibits the spread of diseases. So since pastors just like everyone else have access to technology they are also well aware of the issues facing the world today, they should engage with them critically. Pastors should not hide anything but engage youth classes, say in age ranges of 10-13, 13-16, 16-20. They should discuss circumcision so that the church would raise an informed generation that will be critical of any health innovation.

Similarly, a member of the CSC said pastors in his church did not speak about it, but went on to say, "I'm not sure if they should. I think the church should discuss such to empower members that are ignorant. This can be done after mass, by inviting either a nurse or anyone from the health sector to give motivational talks." In his eyes, the function of the worship service was to preach the Word of God. Public health messaging fell outside of but could accompany worship services.

Perhaps disheartening for some global health professionals was participants' overriding prediction that the campaign would eventually lose its progressive steam, largely due to what they foresaw as MMC's increasingly unpopularity. Only one woman in the SCC focus group thought that the procedure would continue to gain traction and effect epidemiological change. Participants cited continued disinterestedness, and, conversely, that the more educated people became about it, the more likely they would be to reject it altogether. All the focus groups suggested there might be a small increase in infant MMC, but explained this in terms of the persuasive power of the campaign where promoters would dupe parents into enrolling their children for the procedure. Interestingly, several people in each focus group also reasoned that 
infant circumcision was a violation of children's rights. Namely, parents and promotes co-opted children who lacked an agentive voice to consent. One woman, a CSC member, said,

My predictions are that a few men will circumcise in the near because they will soon discover that circumcision is not a solution to HIV/AIDS.

And on the issue of parents, those that will circumcise their children will be fewer, owing to the fact that some parents would not violate the principle of consent to treatment, which would grant their children the right to make their own independent decision about circumcision.

One young man from an SCC church who underwent the procedure himself, also predicted the overall decline in acceptance and utility, saying "I am a victim to circumcision side effects, and I know what I am talking about," he said, referring to his post-surgical pain. One woman from CSC said, "I think mothers of children will circumcise their babies because of ignorance, and coercion from the promoters." Finally, members of a LAC focus group opined that young men would probably keep going for the procedure versus older men. "Whether one is circumcised or not," one man stated, "we may all suffer similar consequences" of MMC's societal effects.

\section{Discussion}

With respect to Amanze's (2006) depiction of ecumenism, churches with markedly different worship styles, evangelizing objectives, and social histories were able to reconcile diversity on the pressing public issue of HIV and an unconventional means to allay its effects on population health: they were unified, but not necessarily uniform in their responses. Participants understood that variations in opinion on these matters would be inevitable, and that variation evidenced pluralism internal to a wider Christian community who similarly worked against common social challenges. In summary, participants were critical of MMC as a public health 
intervention, seeing the institutions driving the campaign in structurally dependent relationships and interpreting its messaging to negatively influence or complicate men's sexual and cultural norms. While acknowledging a meaningful cultural history of the procedure, participants collectively interpreted circumcision to be a form not pertinent to contemporary Swazi Culture, and instead shored up indigenous forms of bodily adornment as comparable sexual health prevention. Likewise, participants collectively erred toward undertaking metaphorical rather than physical circumcision via New Testament scripture.

The main point of divergence emerged along lines of religious organizations' socioeconomic difference. LACS churches, "older" churches aligned with the Kingship as traditionalist institution, were seen as less likely to take up or promote male medical circumcision. "Newer" "ministry" Pentecostal churches, some aligned with SCC, were seen as more likely to do so based on members' educational level and occupational specialization. Also, these churches' supposed emphasis on "money" aligns with critiques of global health institutions as having financial, rather than actual health prerogatives. Despite these differences, participants noted all people should have more access to educational materials about the procedure, whether in church or not, that could give a critical perspective on the matter so they might make a betterinformed choice to reject MMC. Given the sample size, our findings are not generalizable to the entire (Christian) population of Swaziland yet represent important qualifications to and implications for future studies of MMC and other global health interventions in three areas: local distinctions of "culture" and "religion"; local formations of gender inequality; and how global health inflects religious institutions.

First, most contemporary anthropologists conceptualize "culture" and "religion" as changing, conditional sets of signs and practices used to establish identities and claims for 
belonging. These are attributed value, politicized, and reified as essential properties, as if they were forever unchanging. In this way, "Swazi Culture" tends to get conceptually bounded as a specific set of gendered practices, a specific "tradition" in local terminology, which stands in contrast to Christianity. In consideration of MMC, "Swazi Culture" becomes a ground for selfidentified Christians to eschew the global health campaign as outside of bodily, sexual, and social conventions of what it means to be a contemporary gendered and religious person (Kuper 1973). Some of our interviewees were quite clear about this and the use of the word culture itself in reference to ethno-national identity, repeating what non-Swazi historians have written about the decline of circumcision as a cultural phenomenon in the nineteenth century. ${ }^{4}$ Through the other locally powerful "tradition" of Christianity, circumcision marks other non-Swazi persons' commitment to God. Undergoing circumcision does not evidence Swazi Christian identity, although self-identified Christians are given personal license in their religious "tradition" and from different churches to do the procedure. It is not at all forbidden.

With respect to gender inequality, participants all had reasonable knowledge of MMC, with most mentioning that it is the removal of the foreskin to reduce HIV transmission and high prevalence. However, only the SCC female interviewee and a few members of the CSC focus group said it reduced the risk of female partners developing diseases like cervical cancer, being most likely ignorant of this potential advantage of circumcision or they found it to be too trivial. This unintentional gender bias is typical of a society with enduring patriarchal values like Swaziland, whose skewed power structure shapes values, perceptions, and worldviews about women and men. The celebrated gender's sexual health becomes everyone's concern and protected to ensure continuities of family lineages through children; males are presumed to be independent, aggressive, direct, unemotional, dominant and competent, and the referent point for 
personhood (Nyawo et al. 2013). Correspondingly, medical interventions in a patriarchal space may un-consciously reproduce men's health priorities over women's.

The slogan of the campaign, Soka uncobe ubeliqhawe, or "circumcise and conquer to be a hero"- captures this perception well. For many Swazis to be initially receptive of new concepts like MMC, it becomes culturally defined in a female bias language, which assigns women and men different positions, roles, and behaviors (Nganga 2011: 17). Hegemony, the social dominance of a group, is exercised not through brute force but through a cultural dynamic that extends into private and public realms. Schippers (2007, Jewkes et al. 2015) notes that this legitimates ascendancy and inspires consent in social dominance. Amid enduring cultural forms of patriarchy both men and women criticized the procedure's introduction partly on the basis of its offensive branding, which they saw as shoring up men's sexual predation on women or assumptions of women's sexual pleasure. Similarly, Khumalo (2014: 135) found in interviews with Swazi men that some "misinterpreted the slogan to mean once circumcised they have conquered HIV and AIDS," or perceived themselves to be sexual conquerors. With regards to women's reproductive health, the general perception that males were the key players in the circumcision narrative is therefore shaped by constructions that establish hierarchical relationships between femininity and masculinity.

Emerging at the political and economic intersections of national and international governments and NGOs, the campaign represents a powerful provocation against historical practices of cultural and gender identity. Participants thriftily noted the general importance of the campaign, but a clear disjuncture between circumcision at ideological and epidemiological levels in asking a person to undergo surgery. The "legitimation of biomedical technologies," like MMC, "involves the dissemination of rhetoric about their value; at the most fundamental level, it 
is assumed that they contribute to scientific progress and, further, that they fulfill human 'needs"' (Lock and Nguyen 2010: 23), yet participants perceived that the global program's inception and promotion was removed from their everyday lives. Interestingly, participants also used related global discourses to justify the procedure's delay, namely their stances on children's rights and sexual violence against women as part of the global human rights discourse that circulates in Swaziland's post-2005 constitutional era. Stating that male children must wait until they are adults to circumcise would delay the procedure and enable further education about and encouragement against its eventual undertaking.

Finally, an ecumenical approach revealed how global health comes to inflect objectives and perceptions of local religious institutions. It was clear that newer "ministry" or Pentecostal style churches, some of which align with the SCC, were more supportive of the MMC campaign. Anthropologists paying attention to Pentecostal-charismatic churches note that they are often powerfully transformative institutions. Marshall (2014: S345) describes how the growth of these churches in Africa does not simply reflect institutional diversification nor uniformity: "it is important to remember that for Pentecostals and charismatics, the insistence that they are simply 'Christians' is not always meant as a gesture of ecumenism. It can just as often imply a polemical, indeed apocalyptic claim of the order of 'we and only we are Christians who know and enact the Truth"' about what is right and wrong and what must be done to change circumstances. In Swaziland, like some churches in South Africa (Burchardt 2014, 2015), ministries were seen as fomenting health change, and given license by other churches to go in this direction, however potentially circumspect vis-à-vis global health entities. Collectively, Christians united across the ecumenical spectrum to state that critical reflection of the procedure and further education is necessary before getting cut. 


\section{Conclusion}

The spirit of ecumenism involves religious tolerance of other sects and churches under the theological umbrella of Christ as a saviour and humans' relationship to the divine. Taking this theological perspective on religious pluralism in the Christian context of Swaziland, like elsewhere in Africa, ecumenism offered a lens to move beyond simple statements about presumably uniform religious and cultural influence on health-seeking behaviors and global encounters to better situate reasons for rejection or uptake of MMC with respect to historical, gendered dimensions of the human body, dress, and modes of sexual and social reproduction. While reasons for Christian differences ran across potent axes of education, worldliness, and newness versus traditionalism, these differences did not point to a break down in local religious and sociopolitical fields.

\section{Funding}

Our research was funded in part by the University of the Witwatersrand's Faculty of Humanities and University Research Council and enabled by the University of Swaziland's Faculty of Humanities.

\section{Acknowledgements}

We are thankful to the members of the different churches we interviewed, three anonymous reviewers, and the feedback received from Hebron Ndlovu, Andrea Mariko Grant, and Richard Werbner at the conference "Ecumenical Predicaments and Religious Pluralism in Southern Africa" at the University of Botswana, March 8-11, 2015.

\section{Disclosure Statement}


No potential conflict of professional or financial interest is reported by the authors.

\section{References}

Adams, A., and E. Moyer. 2015. "Sex is Never the Same." Global Public Health 10 (5-6): 721738. doi: 10.1080/17441692.2015.1004356.

Amanze, J. 2006. Ecumenism in Botswana. Gaborone: Pula Press.

Auvert, B., D. Taljaard, E. Lagarde, J. Sobngwi-Tambekou, R. Sitta, and A. Puren. 2005. "Randomized, Controlled Intervention Trial of Male Circumcision for Reduction of HIV Infection Risk.” PLoS Med, 2 (11): e298. doi: 10.1371/journal.pmed.0020298.

Bicego, G., R. Nkambule, I. Peterson, J. Reed, D. Donnell, H. Ginindza, Y. Duong, H. Patel, N. Bock, N. Phillip, C. Mao, and J. Justman. 2013. "Recent Patterns in Population-based HIV Prevalence in Swaziland." PLoS One 8 (10): e77101. doi: 10.1371/journal.pone.0077101.

Bonner, P. 1983. Kings, Commoners and Concessionaires. New York: Cambridge University Press. 
Burchardt, M. 2014. “AIDS Activism in an Age of ARV Treatment in South Africa.” Journal of Southern African Studies 40 (1): 59-74. doi: 10.1080/03057070.2014.877652.

Burchardt, M. 2015. Faith in a Time of AIDS. London: Palgrave-MacMillan.

Dilger, H., M. Burchardt, and R. van Dijk. 2010. "Introduction—The Redemptive Moment: HIV Treatments and the Production of New Religious Spaces." African Journal of AIDS Research 9 (4): 373-383. doi: 10.2989/16085906.2010.545643.

Drain, P., D. Halperin, J. Hughes, J. Klausner, and R. Bailey. 2006. "Male Circumcision, Religion, and Infectious Diseases." BMC Infectious Diseases 6: 172. doi: 10.1186/1471-2334-6172.

Golomski, C. 2015. "Ecumenical Predicaments and Religious Pluralism in Southern Africa." Anthropology News 55 (7-8): 11-12.

Goodale, M. 2006. "Introduction to 'Anthropology and Human Rights in a New Key.'” American Anthropologist 108 (1): 1-8. 
International Religious Freedom Report: Swaziland. 2012. Washington: Bureau of Democracy, Human Rights, and Labor, U.S. Department of State.

Jarrett, P., M. Kliner, and J. Walley. 2014. “Early Infant Male Circumcision for Human Immunodeficiency Virus Prevention." SAHARA-J: Journal of Social Aspects of HIV/AIDS: An Open Access Journal 11 (1): 61-66. doi: 10.1080/17290376.2014.929530.

Jewkes, R., R. Morrell, J. Hearn, E. Lundqvist, J. Blackbeard, G. Lindegger, M. Quayle, Y. Siwekyiya, and L. Gottzén. 2015. "Hegemonic Masculinity.” Culture, Health \& Sexuality 17 (Supplement): 96-111. doi: 10.1080/13691058.2015.1085094.

Johnstone, B. 2007. Discourse Analysis. Malden, MA: Wiley-Blackwell.

Khumalo, T. 2014. “A Socio-cultural Narrative of Male Circumcision in Swaziland.” UNISWA Research Journal 27 (Special Issue): 134-144.

Khumalo-Sakutukwa, G., T. Lane, H. van-Rooyen, A. Chingono, H. Humphries, A. Timbe, K. Fritz, A. Chirowodza, and S. Morin. 2013. "Understanding and Addressing Socio-cultural Barriers to Medical Male Circumcision in Traditionally Non-circumcising Communities in Sub- 
Saharan Africa." Culture, Health \& Sexuality 15 (9): 1085-1100. doi:

$10.1080 / 13691058.2013 .807519$

Kumalo, R.S., ed. 2013. Religion and Politics in Swaziland. Bloemfontein: SUN Press.

Kuper, H. 1973. "Costume and Identity." Comparative Studies in Society and History 15 (3): 348-367. doi: 10.1017/S0010417500007143.

Levin, R. 2000. When Sleeping Grass Awakens. Johannesburg: University of the Witwatersrand Press.

Lock, M, and V.-K. Nguyen. 2010. Anthropology of Biomedicine. Malden: Wiley-Blackwell.

Maibvise, C., and T. Mavundla. 2014. "Reasons for the Low Uptake of Adult Male Circumcision for the Prevention of HIV Transmission in Swaziland.” African Journal of AIDS Research 13 (3): 281-289. doi: 10.2989/16085906.2014.952652.

Marshall, R. 2014. "Christianity, Anthropology, Politics." Current Anthropology 55 (S10): S344S356. doi: $10.1086 / 677737$ 
Mavuso, W. 2015. "Churches Finally Say Yes to Circumcision.” Swazi Observer, January 16.

Mkhwanazi, N. 2016. "Medical Anthropology in Africa." Medical Anthropology 35 (2): 193202. doi: $10.1080 / 01459740.2015 .1100612$

Nganga, T. 2011. Institutions and Gender Inequality. Addis Ababa: OSSREA Publications.

Nyawo, S., S. Nadar, and S. Reddy. 2013. “'Sowungumuntfu ke nyalo'-'You are Now a Real Person': Reproductive Self-Determination in the Context of Reproductive Health in Swaziland." Journal of Gender and Religion in Africa 19 (2): 105-118.

Robbins, J. 2014. "The Anthropology of Christianity." Current Anthropology 55 (S10): S157S171. doi: $10.1086 / 678289$.

Schippers, M. 2007. "Recovering the Feminine Other." Theory \& Society 36 (1): 85-102. doi: 10.1007/s11186-007-9022-4. 
Ssekubugu, R., E. Leontsini, M.J. Wawer, D. Serwadda, G. Kigozi, C.E. Kennedy, F. Nalugoda, R. Sekamwa, J. Wagman and R.H. Gray. 2013. “Contextual Barriers and Motivators to Adult Male Medical Circumcision in Rakai, Uganda." Qualitative Health Research 23 (6): 795-804. doi: $10.1177 / 1049732313482189$.

Smith, A.D. 2012. "Why a U.S. Circumcision Push Failed in Swaziland.” PBS NewsHour July 5.

Wawer, M.J., F. Makumbi, G. Kigozi, D. Serwadda, S. Watya, F. Nalugoda, D. Buwembo, V. Ssempijja, N. Kiwanuka, L.H. Moulton, N.K. Sewankambo, S.J. Reynolds, T.C Quinn, P. Opendi, B. Iga, R. Ridzon, O. Laeyendecker, and R.H. Gray. 2009. "Circumcision in HIVinfected Men and its Effect on HIV Transmission to Female Partners in Rakai, Uganda." Lancet 374 (9685): 229-237. doi: 10.1016/S0140-6736(09)60998-3

Westercamp N. and C. Bailey. 2007. “Acceptability of Male Circumcision for Prevention of HIV/AIDS in Sub-Saharan Africa." AIDS and Behaviour 11 (3): 341-355. doi: 10.1007/s10461006-9169-4.

\section{Notes}

\footnotetext{
${ }^{1}$ The range includes some children and teenagers accompanying parents to the focus group and the parents assenting to their children's participation.
} 
${ }^{2}$ We capitalize Swazi Culture in the sense that it is locally conceptualized as a discrete set of signs and practices that point to formations of national, linguistic, and cultural identity.

${ }^{3}$ For example, in the Old Testment, Genesis 17:11 says: "You are to undergo circumcision, and it will be the sign of the covenant between me and you." Others include Joshua 5:1-3 which reads: “...their hearts melted in fear and they no longer had the courage to face the Israelites. At that time the Lord said to Joshua, "Make flint knives and circumcise the Israelites again." So Joshua made flint knives and circumcised the Israelites at Gibeath Haaraloth.”

${ }^{4}$ Circumcision in the emerging Swazi polity derived from Ngwane cultural influence and served as an organizational mechanism to establish male age-grades or warrior regiments, emabutfo, up until Mswati I stopped the practice in 1845 (Bonner 1983: 24, 41). 